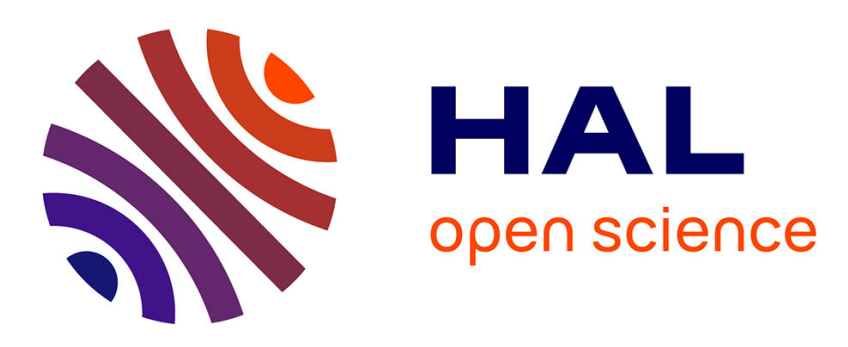

\title{
Physicochemical characterization of pectin grafted with exogenous phenols
}

\author{
Nadine Karaki, Abdulhadi Aljawish, Lionel Muniglia, Catherine Humeau, \\ Jordane Jasniewski
}

\section{- To cite this version:}

Nadine Karaki, Abdulhadi Aljawish, Lionel Muniglia, Catherine Humeau, Jordane Jasniewski. Physicochemical characterization of pectin grafted with exogenous phenols. Food Hydrocolloids, 2016, 60, pp.486-493. 10.1016/j.foodhyd.2016.04.004 . hal-03065592

\section{HAL Id: hal-03065592 https://hal.science/hal-03065592}

Submitted on 16 Apr 2021

HAL is a multi-disciplinary open access archive for the deposit and dissemination of scientific research documents, whether they are published or not. The documents may come from teaching and research institutions in France or abroad, or from public or private research centers.
L'archive ouverte pluridisciplinaire HAL, est destinée au dépôt et à la diffusion de documents scientifiques de niveau recherche, publiés ou non, émanant des établissements d'enseignement et de recherche français ou étrangers, des laboratoires publics ou privés. 


\section{Physicochemical characterization of pectin grafted with exogenous phenols}

2

Nadine Karaki ${ }^{1}$, Abdulhadi Aljawish ${ }^{1}$, Lionel Muniglia ${ }^{1}$, Catherine Humeau ${ }^{2}$ and Jordane Jasniewski ${ }^{*}$

${ }^{1}$ Laboratoire d'Ingénierie des Biomolécules (LIBio), Université de Lorraine, 2 avenue de la Forêt de Haye, F54500 Vandœuvre-lès-Nancy, France

${ }^{2}$ Laboratoire Réactions et Génie des Procédés (LRGP), Université de Lorraine, 2 avenue de la Forêt de Haye, F54500 Vandœuvre-lès-Nancy, France

*Corresponding author: jordane.jasniewski@univ-lorraine.fr

\section{Abstract}

Pectin is a natural polysaccharide, having valuable properties that enable its use in many industrial fields. The aim of this work was to study the impact of pectin modification with phenols, on the properties of this biopolymer. Results suggested that the enzymatic grafting of ferulic acid (FA) oxidation products onto the pectin altered its morphological surface and its thermal properties. Moreover, modified pectin showed a less hygroscopic behavior when water activity is less than 0.50 and a higher ability to bound water above 0.5 . Additionally, modified pectin became less viscous than the native pectin and presented different calciumdependent gelation behavior. Finally, a significant improvement of the antioxidant properties of pectin after functionalization was observed. As a conclusion, the modification of pectin with phenolic compounds appeared as a promising way to produce a polysaccharide with new properties that could enlarge the field of its potential applications.

Keywords: pectin; ferulic acid; functionalization; antioxidant; rheology; hygroscopy. 


\section{Introduction}

Pectin is an anionic high-molecular weight polysaccharide commercially extracted from the cell wall of citrus peel, apple pomace and sugar beet (Qiu, Tian, Qiao, \& Deng, 2009). It is composed of a linearly $\alpha$-1,4-linked D-galacturonic acid residues backbone interrupted occasionally by (1,2)-linked rhamnose residues (Ridley, O’Neill, \& Mohnen, 2001). Pectin is well known for its gelling and thickening properties that justify its extensive use as a food ingredient. Many studies reported the existence of a correlation between the chemical structure of pectin and its techno-functional properties (Chen et al., 2015; Sila et al., 2009). The esterification and acetylation degrees of pectin appear as crucial structural characteristics that are mostly exploited to produce biopolymers with modulated properties (Buchholt, Christensen, Fallesen, Ralet, \& Thibault, 2004; Cheng \& Gu, 2012; van den Broek \& Boeriu, 2013). Such modifications were performed aiming to overcome the major drawbacks of pectin (formation of lumps, swelling behavior, hydrophilic nature) when used in some specific areas (Kurita, Miyake, \& Yamazaki, 2012). Another approach was described using a laccasecatalyzed oxidation reaction of feruloylated sugar beet pectin. In this reaction, endogenous ferulic acid units were oxidized leading to reactive semiquinones that can subsequently form ferulic acid dimers allowing pectin crosslinking. The crosslinked structures have showed improved rheological properties (Kuuva, Lantto, Reinikainen, Buchert, \& Autio, 2003; Zaidel, Chronakis, \& Meyer, 2012), useful for the preparation of in situ hydrogels (Takei, Sugihara, Ijima, \& Kawakami, 2011) or for the formation of stable emulsions (Zaidel \& Meyer, 2013). This approach was also applied to conjugate sugar beet pectin with proteins. In this case, the protein solubility in water was enhanced at its isoelectric point, avoiding its precipitation (Jung \& Wicker, 2012). As reported by several studies, laccases could also be used to enrich polysaccharides with phenols. In this instance, semiquinones generated from laccase-catalyzed oxidation of exogenous phenols reacted with nucleophilic functions present 
in the reaction medium leading to their grafting onto the polysaccharide chains (Elegir, Kindl, Sadocco, \& Orlandi, 2008; Y. Liu et al., 2014; Torres et al., 2012).

The main scientific issue related to this work was to compare the physical-chemical properties of native pectin with those of pectin modified with exogenous phenolic species issued from laccase-catalyzed oxidation of ferulic acid. The color, the thermal and hygroscopic behavior, the morphological state, the rheological properties and the antioxidant capacity were more specifically studied for a qualitative and/or quantitative examination of the polysaccharide.

\section{Materials and methods}

\subsection{Chemicals and enzyme}

Citrus pectin with galacturonic acid $\geq 74.0 \%$ (dried basis) and with a methoxylation degree $\geq 6.7 \%$, ferulic acid (FA), and 2,2'-azino-bis (3-éthylbenzothiazoline-6-acide sulfonique) (ABTS) were purchased from Sigma-Aldrich (France). The following chemicals 1,1-Diphenyl-2-picrylhydrazyl (DPPH), methanol, ethanol and acetone were obtained from Carlo Erba (Milwaukee, WI, USA).

An industrial laccase named Suberase ${ }^{\circledR}$ (Novo Nordisk A/S, Bagsvaerdt, Denmark) was bought from the Society Novozymes under liquid form. The Suberase ${ }^{\circledR}$ is a fungal laccase from Myceliophthora thermophila sp., which is considered as a member of family of polyphenol oxidases, produced by submerged fermentation of a genetically modified Aspergillus oryzae. The enzymatic preparation was supplied as a brown liquid with a density of approximately 1.15 g.mL $\mathrm{mL}^{-1}$. It was completely miscible with water. Laccase activity is 13.5 $\mathrm{UI} / \mathrm{mL}$.

The pectin was functionalized with laccase-mediated oxidation products of ferulic acid according to the method described by Aljawish et al. (2012). Briefly, the modification reaction was performed at $30{ }^{\circ} \mathrm{C}$ by the addition of $5 \mathrm{ml}$ of methanol solution of ferulic acid 
$50 \mathrm{mM}, 1 \mathrm{~g}$ of low methoxyl pectin and $45 \mathrm{ml}$ of phosphate buffer $(50 \mathrm{mM}, \mathrm{pH} 7.5)$ in the reactor. The addition of $13.5 \mathrm{UI} / \mathrm{mL}$ of Suberase ${ }^{\circledR}$ (a fungal laccase from Myceliophthora thermophila) trigger the reaction, which was carried out for four hours. The reaction medium was then kept in a freezer for $24 \mathrm{~h}$, then freeze-dried for $72 \mathrm{~h}$. Next, the powder was washed with organic solvents (methanol, ethanol and acetone) to remove unbounded phenols that could be adsorbed onto pectin through electrostatic interactions. Finally, the powder was kept in a desiccator until use.

\subsection{Physicochemical properties}

\subsubsection{Thermal Analyses}

Before analysis, all samples were dried at room temperature in a desiccator, containing $\mathrm{P}_{2} \mathrm{O}_{5}$ as drying agent, for at least one week. The differential scanning calorimetry measurement was carried out using a DSC (DSC 204 F1 Phoenix, Netzsch, Germany) under dynamic inert nitrogen atmosphere, with a flow rate of $4 \mathrm{ml} / \mathrm{min}$. Approximately $10 \mathrm{mg}$ of pectin powders were weighted in an aluminum capsule and placed in the DSC system in parallel to an empty capsule used as reference. The program was fixed to perform a first round of heating from 0 to $200{ }^{\circ} \mathrm{C}$ in a $5 \mathrm{~K} / \mathrm{min}$ rate, followed by a cooling from 200 to $0{ }^{\circ} \mathrm{C}$ at the same rate $5 \mathrm{~K} / \mathrm{min}$. Then a second heating from 0 to $300{ }^{\circ} \mathrm{C}$ at $5 \mathrm{~K} / \mathrm{min}$ was performed. All runs were performed at least in triplicate.

\subsubsection{Surface analyses}

The morphologies of native pectin and pectin grafted with phenols were observed using a Hitachi scanning electron microscopy (SEM) S4800. Before testing, the samples were evaporated with carbon and then coated with gold, to make the samples conductive. SEM was performed under high vacuum at an accelerating voltage of $10 \mathrm{kV}$. The microphotographs were taken using automatic image capture software.

\subsubsection{Water sorption isotherms}


The Dynamic Vapor Sorption was used to monitor the moisture sorption capacity of pectin powders as a function of water activity (aw). Measuring the water sorption, provided information about the physical and chemical stability of the sample under given storage conditions. Water sorption isotherms were determined gravimetrically using a DVS apparatus (Surface Measurement Systems, London, UK) equipped with a Cahn microbalance. The changes in sample weight over time at $25{ }^{\circ} \mathrm{C}$ and at any desired aw (between 0 and 0.9 ) were recorded. About 70 to $80 \mathrm{mg}$ of sample were loaded onto the quartz sample pan. The program was initially set to control the water activity at 0 for $12 \mathrm{~h}$ (drying phase). This step allowed the sample water activity to decrease to zero and internally equilibrate. The sample was then subjected to successive steps of 0.1 aw increase, up to 0.9 . For each step, the mass changes (m) and the rate of mass changes $(\mathrm{dm} / \mathrm{dt})$ were plotted against time. The equilibrium was considered to be reached when changes in mass with time were lower than $0.001 \%$ total weight/min (i.e. $1 \mathrm{~g}$ water/100 $\mathrm{g}$ dry basis/day). All experiments were performed at $25{ }^{\circ} \mathrm{C}$ and 3 tests were carried out for each sample. The accuracy of the system was \pm 0.01 aw and \pm 0.2 ${ }^{\circ} \mathrm{C}$, respectively.

The rate at which the material equilibrated at each humidity level, as well as the overall shape of the resulting adsorption profile, provided useful information about the structure material and long-term stability.

\subsubsection{Rheological measurements}

\subsubsection{Viscosity measurements}

The viscosity of solutions prepared in deionized water $(\mathrm{pH}$ 6.5) with several concentrations (from $1 \%$ to $4 \% \mathrm{w} / \mathrm{v}$ ) of native and modified pectin were determined using a Kinexus rotative rheometer (Malvern Instruments, KNX 2100, UK) with a cone-plate geometry $\left(50 \mathrm{~mm}\right.$ of diameter, angle of $\left.2^{\circ}\right)$, at constant temperature $\left(25^{\circ} \mathrm{C}\right)$, just after the pectin solutions were prepared. The shear rate was increased from 0.001 to $100 \mathrm{~s}^{-1}$. The 
Newtonian and power law models were used to analyze the rheological behavior of the samples. Each viscosity measurement was performed in triplicate. The temperature was controlled by a Peltier system and the sample was covered with paraffin oil to avoid evaporation.

\subsubsection{Oscillation measurements}

Oscillatory measurements were used to determine the storage modulus $\left(G^{\prime}\right)$ and loss modulus $\left(G^{\prime \prime}\right)$ of $2 \%$ pectin solutions using a $50 \mathrm{~mm}$ parallel plate at $25^{\circ} \mathrm{C}$. Strain sweep $(0.01-100 \%$ at $1 \mathrm{~Hz})$ was applied to test the linear viscoelastic region of the samples. The frequency dependence of $G^{\prime}$ and $G^{\prime \prime}$ was determined by a frequency sweep $(0.1-30 \mathrm{~Hz}$ at $1 \%$ strain) (Zhang et al., 2013).

\subsubsection{Gelation rate determination}

$2 \mathrm{ml}$ of solutions with $12.5 \mathrm{~g}$ of native and modified pectin were prepared in $0.1 \mathrm{M}$ $\mathrm{NaCl}$, in order to screen electrostatic interactions. The $\mathrm{pH}$ was adjusted to 6.5 to obtain fully charged chains (Capel, Nicolai, Durand, Boulenguer, \& Langendorff, 2006). Then, a certain amount of $\mathrm{CaCl}_{2}$ which corresponded to $\mathrm{R}=\left(2\left[\mathrm{Ca}^{2+}\right]\right) /\left(\left[\mathrm{COO}^{-}\right]\right)=0.58$ was added to the pectin solutions (Fu \& Rao, 2001). The solutions were immediately loaded onto the rheometer cone-plane geometry and $G^{\prime}$ and $G^{\prime \prime}$ shear modulus at $1 \mathrm{~Hz}$ and $0.001 \%$ strain were monitored. The strain was determined by a strain sweep test from 0.0001 to $10 \%$. The frequency was determined by a frequency sweep test from 0.01 to $100 \mathrm{~Hz}$ performed on the gels after its formation to determine and compare the storage and loss moduli $\left(G^{\prime}\right.$ and $G^{\prime \prime}$, respectively). Rheological measurements were performed in three replicates.

\subsection{Antiradical activity measurements}

\subsubsection{DPPH ${ }^{\bullet}$ free radical scavenging activity}

Several amounts of pectin powder (from 0.5 to $40 \mathrm{mg}$ ) were added into the cuvette filled with the solution containing $\mathrm{DPPH}^{\bullet}$ radicals $\left(6.10^{-5} \mathrm{M}\right)$ resulting in a final concentration of 
$0.5-40 \mathrm{mg} / \mathrm{ml}$ of pectin. After incubation for $30 \mathrm{~min}$ at room temperature in the dark, the absorbance $\left(A_{\mathrm{i}}\right)$ at $517 \mathrm{~nm}$ was measured using an UV-Vis spectrometer (Shimadzu UV-1605) against a blank without pectin, according to the slightly modified method of (Guo et al., 2015). The scavenging ability was calculated by the Equation 1 :

Equation 1: DPPH Scavenging ability $(\%)=(1-$ Abs sample /Abs control $) \times 100$

The $\mathrm{EC}_{50}$ value, which expressed the antioxidant concentration required to reduce the radicals by $50 \%$, is a good indicator to quantify the antioxidant capacity. Each value represents the average \pm standard deviation of three independent experiments.

\subsection{2. $\mathrm{ABTS}^{\bullet+}$ radical cation decolorization assay}

The ABTS $^{*+}$ radical scavenging activity method was based on the ability of one compound to quench the $\mathrm{ABTS}^{*+}$ radical cation. $\mathrm{ABTS}^{\circ+}$ species were produced by the reaction between ABTS $(7 \mathrm{mM})$ and potassium persulfate $(2.45 \mathrm{mM})$ in ratio 1:1 dissolved in water. The mixture was kept in the dark overnight, and then diluted with ethanol until an absorbance of $0.7 \pm 0.25$ at $734 \mathrm{~nm}$ was obtained. Several concentrations varying from 0.5 to $20 \mathrm{mg} / \mathrm{ml}$ of pectin solubilized in distilled water were mixed with $1 \mathrm{ml}$ of $\mathrm{ABTS}^{*+}$ solution. After $30 \mathrm{~min}$ in the dark at room temperature, the absorbance at $734 \mathrm{~nm}$ was measured (Re et al., 1999) and the scavenging capability was calculated using the Equation 2:

Equation 2: $\operatorname{ABTS}^{\circ+}$ radical scavenging activity $(\%)=(1-$ Abs sample /Abs control $) \times 100$

$\mathrm{ABTS}^{\circ+}$ radical scavenging activity was expressed as $\mathrm{EC}_{50}$ value, which corresponded to the antioxidant concentration capable of reducing $50 \%$ of the $\mathrm{ABTS}^{\circ+}$ radicals. All analyses were carried out in triplicate; results represented the mean values with standard deviation.

\subsection{Statistical analysis}

The experimental results were performed in triplicate. The data were recorded as means \pm standard deviation (SD) and analyzed by SPSS (version 11.5 for Windows 2000, SPSS Inc.). 
One-way analysis of variance was performed by ANOVA procedures. Significant differences between means were determined by Duncan's Multiple Range tests. Differences at $p<0.05$ were considered significant.

\section{Results and discussion}

\subsection{Physicochemical properties of pectin derivative}

\subsubsection{Thermal analyses}

Thermal analysis of polymers provides characteristic data related to time and temperature. The determination of temperature and heat flows associated with thermal transitions give useful information about the properties and the end-use performances of materials. In the present study, thermal analyses were performed to characterize pectin powders, in order to evaluate the effect of functionalization on the molecular arrangement of pectin chains and their interactions. Differential scanning calorimetry (DSC) was used to study thermal transitions occurring in the course of heating of pectin powders. A first run from 0 to $200{ }^{\circ} \mathrm{C}$ was made to remove all traces of water. Indeed, as shown by several authors, a peak around $100{ }^{\circ} \mathrm{C}$ was attributed to water evaporation, in citrus pectin samples (Einhorn-Stoll, Kunzek, \& Dongowski, 2007). Similar results were obtained with sugar beet pectin (Combo et al., 2013), apple peel pectin (Godeck, Kunzek, \& Kabbert, 2001; Monfregola, Bugatti, Amodeo, De Luca, \& Vittoria, 2011) and products containing pectin (Osorio, Carriazo, \& Barbosa, 2011 ). Results obtained after the second run of heating are shown in Table 1. Differences at $p<0.05$ were considered to be significant.

For the native pectin, a glass transition was observed at $60{ }^{\circ} \mathrm{C}$ against $48{ }^{\circ} \mathrm{C}$ for the modified pectin $(p<0.05)$. These results appeared somewhat higher than the glass transition temperature of low or high methoxyl pectins $\left(37{ }^{\circ} \mathrm{C}\right)$ reported by (Iijima, Nakamura, Hatakeyama, \& Hatakeyama, 2000). A weak exothermic peak corresponding to crystallization was observed in the pectin grafted with phenols at $130{ }^{\circ} \mathrm{C}$ whereas no similar transition was 
detected in native pectin. Such results suggested that pectin became under an amorphous form once the crystalline pectin was melted (Iijima et al., 2000). The endothermic peak observed at $180{ }^{\circ} \mathrm{C}$ and $160{ }^{\circ} \mathrm{C}$ in native and modified pectin, respectively, was ascribed to the melting transition phase. These results were consistent with those described by other authors who found a melting temperature of citrus pectin around $180{ }^{\circ} \mathrm{C}$ (Pereira, Carmello-Guerreiro, \& Hubinger, 2009), at $200{ }^{\circ} \mathrm{C}$ (Osorio et al., 2011), or at $152{ }^{\circ} \mathrm{C}$ (Iijima et al., 2000). Moreover, several exothermic peaks were found from $180{ }^{\circ} \mathrm{C}$ for the modified pectin and $225{ }^{\circ} \mathrm{C}$ for the native one. These peaks were attributed to the degradation of the polymer followed by the elimination of volatile products. At such temperatures, the degradation was primarily derived from pyrolytic decomposition and decarboxylation pathways (Calce, Bugatti, Vittoria, \& De Luca, 2012).

In view of these results, the pectin grafted with phenols appeared as a less organized polysaccharide compared with the native pectin. This was explained by the incorporation of phenolic entities that might disorder, and then destabilize the overall structure of the polymer. Phenolic entities were suspected to increase the free volume between the polysaccharide chains, thus limiting their interactions. Depending on target applications, the thermal behavior of the pectin grafted with phenols could be either an advantage or a limitation, when compared to the native polysaccharide.

\subsubsection{Morphology analyses}

Morphological analysis is considered as an efficient method to study the shape of particles, and then to explain their behavior and some of their physicochemical properties. The morphology of pectin particles was shown in Figure 1. 
According to the SEM images, the native pectin exhibited a rough surface contrary to the pectin grafted with phenols that presented a smooth surface. These observations highlighted the impact of the functionalization of pectin on the organization of the polysaccharide chains.

Similar findings were reported in the case of starch granules functionalized through an enzymatic esterification process (Lin, Li, Long, Su, \& Huang, 2015). Grafting of rosin acid occurred in the non-stereotyped area of starch and inside the crystalline regions making the granules less organized. The morphology as well as the crystallinity of starch was affected by the structural modifications brought to the polysaccharide.

\subsubsection{Water sorption isotherms}

Phenolic compounds are known to present a hydrophobic character. Their grafting onto the pectin hydrophilic chains was expected to affect the affinity of the polysaccharide for water as well as the overall structure of the polysaccharide. Moisture sorption isotherms of native and modified pectin powders were determined (Figure 2).

The isotherm profile is conventionally divided into three zones. The first one corresponding to the monolayer strongly bound water, this zone usually gives an idea of the hygroscopic character of the substance. The second zone attributed to the linear region of capillary adsorbed water which was more loosely bound, and in the third zone excess free water was present in macrocapillaries (Mathlouthi, 2001; Saad et al., 2014). The profile obtained with the native pectin was a slight sigmoid that reflected a Type II isotherm suggesting a growing equilibrium moisture content with increasing water activity according to the classification of (Brunauer, Deming, Deming, \& Teller, 1940; Ricardo, Andrade, Lemus M, Carmen, \& Perez, 2011). The pectin grafted with phenols presented a J-shaped type III isotherm, that accounted for a plasticizer effect of water at high $\mathrm{a}_{\mathrm{w}}$ values (Andrade P., Lemus M., \& Pérez C., 2011). The monolayer moisture content $\left(\mathrm{M}_{0}\right)$ gave a good representation of 
the hygroscopic behavior of polymers. It could be determined graphically as the tangent to the adsorption curve when the first layer of water saturated all the sites of pectin $\left(0.0<\mathrm{a}_{\mathrm{w}}<0.1\right)$. $\mathrm{M}_{0}$ of the modified pectin was lower $(1.9 \mathrm{~g} / 100 \mathrm{~g}$ dry bases) than that of the native pectin (5 $\mathrm{g} / 100 \mathrm{~g}$ dry bases); suggesting the presence of less sorption sites accessible to water in modified pectin and thus a less hygroscopic nature. These data were consistent with the fact that the pectin grafted with phenols was somewhat more hydrophobic than the native one. Furthermore, native pectin particles have a larger specific surface (rough surface) capable of adsorbing more water than that of the modified pectin particles (smooth surface).

In addition, a transformation of the material of modified pectin seemed to occur above the critical $a_{w}$ value of 0.45 . The isotherm profile suggested a change from the amorphous glassy state to the amorphous rubbery state. At high $\mathrm{a}_{\mathrm{w}}$ values, the growing capacity of the modified pectin to absorb water could be explained by the open structure of the polysaccharide. As a plasticizer, the water molecules can be inserted between the polymer chains, thereby increasing the free volume and weakens the interchain interactions (Basu, Shivhare, \& Muley, 2013; Roos \& Karel, 1990). On the contrary, the native pectin seemed to maintain its structure when increasing water activity.

Some authors correlated the capacity of pectin to bind water with the degree of esterification (DE). Wallingford \& Labuza, 1983 found that low methoxyl pectin absorbed more water than high meyhoxyl pectin for a given water activity. This result was inconsistent with other studies reporting an opposite trend (Panchev, Slavov, Nikolova, \& Kovacheva, 2010; Tsami, Vagenas, \& Marinos-Kouris, 1992). These contradictory results suggested that no direct correlation existed between the DE and the water adsorption capacity of pectin. In our case, the DE of the modified pectin was higher than that of the native polysaccharide due to the grafting of phenolic compounds. Considering the hydrophobic nature of phenols, the 
less hygroscopic nature of the modified pectin appeared as a logical consequence of its higher DE.

In the present study, the functionalization of pectin with phenols led to a less hygroscopic polysaccharide at low water activities. This could constitute an advantage for storage. For higher water activities, the less compact organization of the modified pectin compared to the native one allowed water to act as a plasticizer, thus facilitating the dispersion of the polysaccharide.

\subsubsection{Rheological measurements}

\subsubsection{Viscosity of pectin solutions}

The viscosity of the two pectin solutions decreased with increasing the shear rate. This was caused by the random coil of pectin polysaccharide, demonstrating a shear-thinning character, with a flow behavior index $(\eta)$ lower than 1 (Figure 3). Hence, native and modified pectin were considered as pseudoplastic fluids (L. Liu, Cao, Huang, Cai, \& Yao, 2010; X. Wang, Chen, \& Lü, 2014; Zhang et al., 2013).

The two curves showed differences in their flow behavior patterns. Overall, the native pectin had a slightly higher viscosities than the pectin grafted with phenols, whatever the shear rate. Furthermore, the native pectin had a shorten power-law region. At shear rates superior to $0.0325 \mathrm{~s}^{-1}$, the native pectin started to behave like a Newtonian fluid where the apparent viscosity was relatively constant. For the modified pectin, a slightly higher resistance to shearing was observed $\left(0.0511 \mathrm{~s}^{-1}\right)$. This behavior could be explained by the presence of phenolic entities interacting within the pectin structure. Another assumption could be related to the molecular weight of the two types of pectin (Yuan, Galloway, Hoffman, \& Bhatt, 2011). The shear-thinning behavior of the two solutions was a consequence of the physical disruption of chain entanglements which required time to be formed (S.-Q. Wang, Ravindranath, Wang, \& Boukany, 2007). 
The viscosity was also determined depending on the polymer concentration. A shear rate value of $2.78 .10^{-4} \mathrm{~s}^{-1}$ was chosen so that both pectins adopted a shear-thinning behavior

(Figure 4). The slope in the shear thinning regions was correlated with the concentration.

At low concentration, the solutions prepared with the native and the modified pectins presented similar viscosities. Whatever was the pectin type, the increase of concentration led to an increased viscosity, indicating that the freedom of movement of individual chains became restricted (Morris, Cutler, Ross-Murphy, Rees, \& Price, 1981; Sousa, Nielsen, Armagan, Larsen, \& Sørensen, 2015). Moreover, the solution of pectin grafted with phenols became less viscous than that of the native pectin. This trend was even more pronounced as the concentration increased.

\subsubsection{Oscillation measurements of pectin solutions}

At low frequency, both types of pectin exhibited the typical behavior of polysaccharide in solution. The viscous modulus $\left(G^{\prime \prime}\right)$ was higher than the elastic modulus $\left(G^{\prime}\right)$, indicating the predominance of the viscous properties due to the dynamic balance between pectin molecular entanglement and shearing (Figure 5).

When the frequency increased, $G$ ' and $G$ ' crossed, indicating the viscoelastic behavior of pectin. The crossover point indicates the exact frequency leading to elastic behavior or approaching gel state (Zhang et al., 2013). These values were similar for the two types of pectin $(0.67 \mathrm{~Hz}$ and $0.69 \mathrm{~Hz})$. The crossover point was correlated to the degree of elasticity and more particularly to the relaxation time that corresponds to the time needed to regain the original configuration (Choi, 2008). After the crossover point, $G$ ' became greater than $G$ '”. This trend was explained by the orientation of the polymeric chains leading to a gel (Peressini, Bravin, Lapasin, Rizzotti, \& Sensidoni, 2003; Piermaria, de la Canal, \& Abraham, 2008; X. Wang et al., 2014). 


\subsubsection{Gelation rate determination}

The influence of calcium addition on the gelation behavior of both types of pectin was studied by monitoring the evolution of the storage modulus $\left(G^{\prime}\right)$ with time. The gel set time was determined as the time at which $G^{\prime}>1$ Pa.s (Urias-Orona et al., 2010).

The native pectin prepared in phosphate buffer form a gel immediately after the addition of calcium, whereas the modified polysaccharide required more time (2871 s) (Figure 6). This result could be explained by fewer interactions between the modified pectin and calcium ions compared to the native polysaccharide, and then leading to a slow-set gelation (Löfgren, Guillotin, Evenbratt, Schols, \& Hermansson, 2005). The modified pectin is particularly interesting in food industry a gelling agent for the production of clear jellies from clarified fruit juices such as grape juice.

The difference observed in the kinetic of gel formation for the two types of pectin was explained by the chemical modifications and the subsequent conformational changes brought to the polysaccharide due to its functionalization. All these results suggested that the enzymatically modified pectin has a higher degree of methyl esterification resulting in the availability of fewer carboxyl groups to interact with calcium ions to form the egg box architecture, and thus the gel.

\subsection{In vitro antioxidant properties}

The functionalization of pectin was expected to increase its antioxidant capacity due to the incorporation of phenolic entities that can act as a hydrogen or electron donors (Li et al., 2012; Molyneux, 2004). The ability of the pectin grafted with phenols to quench radical species such as $\mathrm{DPPH}^{\circ}$ and the $\mathrm{ABTS}^{\circ}$ was studied and then compared to that of the native pectin. The scavenging activity of the native and the modified pectin was shown in Table 2 . Differences at $p<0.05$ were considered to be significant. 
Whatever the radical species, the $\mathrm{EC}_{50}$ values obtained with the modified pectin was much lower than those observed for the native pectin, indicating a higher antioxidant capacity $(p<0.05)$. This result could be explained by the grafting of phenolic entities produced from the laccase-mediated oxidation of ferulic acid. Similar results were reported in the case of other polymers grafted with ferulic acid oxidation products (Aljawish et al., 2012, 2014; García-Zamora et al., 2015). The weak antioxidant activity observed for the native pectin was attributed to few ferulic acid units naturally present in its structure.

In view of these results, the functionalization of pectin with phenols appeared as a promising way to produce new polyfunctional derivatives with improved properties that are expected to broaden the scope of polysaccharides.

\section{Conclusion}

In the present study, the physicochemical properties of pectin grafted with phenolic compounds were investigated and compared to those of the native pectin. This work demonstrated significant relationships between the structure of the polymer and its properties. Experimental evidence demonstrated clearly that the modification of pectin with ferulic acid oxidation products affected the organization of the polysaccharide chains and certainly also their interactions. The introduction of phenol entities within the polymer structure increased its hydrophobicity as well as its antioxidant activity and led to a looser organization. The capacity to adsorb water and the rheological properties of pectin were also affected by the functionalization, which could be either an advantageous or a drawback, depending on the target applications. In any case, the grafting of phenols onto pectin polymeric chains allowed modulating and even improving the techno-functional properties of the polysaccharide. Thanks to its antioxidant activity and its physico-chemical properties, the modified pectin appeared as a promising polyfunctional ingredient. 


\section{References}

Aljawish, A., Chevalot, I., Jasniewski, J., Revol-Junelles, A.-M., Scher, J., \& Muniglia, L. (2014). Laccase-catalysed functionalisation of chitosan by ferulic acid and ethyl ferulate: evaluation of physicochemical and biofunctional properties. Food Chemistry, 161, 279-287.

Aljawish, A., Chevalot, I., Piffaut, B., Rondeau-Mouro, C., Girardin, M., Jasniewski, J., Scher, J., Muniglia, L. (2012). Functionalization of chitosan by laccase-catalyzed oxidation of ferulic acid and ethyl ferulate under heterogeneous reaction conditions. Carbohydrate Polymers, 87(1), 537-544.

Andrade P., R. D., Lemus M., R., \& Pérez C., C. E. (2011). Models of sorption isotherms for food: uses and limitations. Vitae, 18(3), 325-334.

Basu, S., Shivhare, U. S., \& Muley, S. (2013). Moisture adsorption isotherms and glass transition temperature of pectin. Journal of Food Science and Technology, 50(3), 585-589.

Brunauer, S., Deming, L. S., Deming, W. E., \& Teller, E. (1940). On a Theory of the van der Waals Adsorption of Gases. Journal of the American Chemical Society, 62(7), 1723-1732.

Buchholt, H. C., Christensen, T. M. I. E., Fallesen, B., Ralet, M.-C., \& Thibault, J.-F. (2004). Preparation and properties of enzymatically and chemically modified sugar beet pectins. Carbohydrate Polymers, 58(2), 149-161.

Calce, E., Bugatti, V., Vittoria, V., \& De Luca, S. (2012). Solvent-Free Synthesis of Modified Pectin Compounds Promoted by Microwave Irradiation. Molecules, 17(12), 12234-12242.

Capel, F., Nicolai, T., Durand, D., Boulenguer, P., \& Langendorff, V. (2006). Calcium and acid induced gelation of (amidated) low methoxyl pectin. Food Hydrocolloids, 20(6), 901907.

Cheng, H. N., \& Gu, Q.-M. (2012). Enzyme-Catalyzed Modifications of Polysaccharides and Poly(ethylene glycol). Polymers, 4(4), 1311-1330.

Chen, J., Liu, W., Liu, C.-M., Li, T., Liang, R.-H., \& Luo, S.-J. (2015). Pectin modifications: a review. Critical Reviews in Food Science and Nutrition, 55(12), 1684-1698.

Choi, S. K. (2008). PH Sensitive Polymers for Novel Conformance Control and Polymer Flooding (PhD thesis). University of ProQuest.

Combo, A. M. M., Aguedo, M., Quiévy, N., Danthine, S., Goffin, D., Jacquet, N., Blecker, C., Devaux, J., Paquot, M. (2013). Characterization of sugar beet pectic-derived oligosaccharides obtained by enzymatic hydrolysis. International Journal of Biological Macromolecules, 52, $148-156$.

Einhorn-Stoll, U., Kunzek, H., \& Dongowski, G. (2007). Thermal analysis of chemically and mechanically modified pectins. Food Hydrocolloids, 21(7), 1101-1112.

Elegir, G., Kindl, A., Sadocco, P., \& Orlandi, M. (2008). Development of antimicrobial cellulose packaging through laccase-mediated grafting of phenolic compounds. Enzyme and Microbial Technology, 43(2), 84-92.

Fu, J.-T., \& Rao, M. A. (2001). Rheology and structure development during gelation of lowmethoxyl pectin gels: the effect of sucrose. Food Hydrocolloids, 15(1), 93-100. 
García-Zamora, J. L., Sánchez-González, M., Lozano, J. A., Jáuregui, J., Zayas, T., Santacruz, V., Hernández, F., Torres, E. (2015). Enzymatic treatment of wastewater from the corn tortilla industry using chitosan as an adsorbent reduces the chemical oxygen demand and ferulic acid content. Process Biochemistry, 50(1), 125-133.

Godeck, R., Kunzek, H., \& Kabbert, R. (2001). Thermal analysis of plant cell wall materials depending on the chemical structure and pre-treatment prior to drying. European Food Research and Technology, 213(4-5), 395-404.

Guo, M., Ma, Y., Wang, C., Liu, H., Li, Q., \& Fei, M. (2015). Synthesis, anti-oxidant activity, and biodegradability of a novel recombinant polysaccharide derived from chitosan and lactose. Carbohydrate Polymers, 118, 218-223.

Iijima, M., Nakamura, K., Hatakeyama, T., \& Hatakeyama, H. (2000). Phase transition of pectin with sorbed water. Carbohydrate Polymers, 41(1), 101-106.

Jung, J., \& Wicker, L. (2012). Laccase mediated conjugation of sugar beet pectin and the effect on emulsion stability. Food Hydrocolloids, 28(1), 168-173.

Kurita, O., Miyake, Y., \& Yamazaki, E. (2012). Chemical modification of citrus pectin to improve its dissolution into water. Carbohydrate Polymers, 87(2), 1720-1727.

Kuuva, T., Lantto, R., Reinikainen, T., Buchert, J., \& Autio, K. (2003). Rheological properties of laccase-induced sugar beet pectin gels. Food Hydrocolloids, 17(5), 679-684.

Lin, R., Li, H., Long, H., Su, J., \& Huang, W. (2015). Structure and characteristics of lipasecatalyzed rosin acid starch. Food Hydrocolloids, 43, 352-359.

Liu, L., Cao, J., Huang, J., Cai, Y., \& Yao, J. (2010). Extraction of pectins with different degrees of esterification from mulberry branch bark. Bioresource Technology, 101(9), 32683273 .

Liu, Y., Zhang, B., Javvaji, V., Kim, E., Lee, M. E., Raghavan, S. R., Wang, Q., Payne, G. F. (2014). Tyrosinase-mediated grafting and crosslinking of natural phenols confers functional properties to chitosan. Biochemical Engineering Journal, 89, 21-27.

Li, W. J., Cheng, X. L., Liu, J., Lin, R. C., Wang, G. L., Du, S. S., \& Liu, Z. L. (2012). Phenolic Compounds and Antioxidant Activities of Liriope muscari. Molecules, 17(2), 17971808 .

Löfgren, C., Guillotin, S., Evenbratt, H., Schols, H., \& Hermansson, A.-M. (2005). Effects of calcium, $\mathrm{pH}$, and blockiness on kinetic rheological behavior and microstructure of HM pectin gels. Biomacromolecules, 6(2), 646-652.

Mathlouthi, M. (2001). Water content, water activity, water structure and the stability of foodstuffs. Food Control, 12(7), 409-417.

Molyneux, P. (2004). The use of the stable free radical diphenylpicrylhydrazyl (DPPH) for estimating antioxidant activity. Songklanakarin J. Sci. Technol., 26(2), 211-219.

Monfregola, L., Bugatti, V., Amodeo, P., De Luca, S., \& Vittoria, V. (2011). Physical and water sorption properties of chemically modified pectin with an environmentally friendly process. Biomacromolecules, 12(6), 2311-2318. 
Morris, E. R., Cutler, A. N., Ross-Murphy, S. B., Rees, D. A., \& Price, J. (1981). Concentration and shear rate dependence of viscosity in random coil polysaccharide solutions. Carbohydrate Polymers, 1(1), 5-21.

Osorio, C., Carriazo, J. G., \& Barbosa, H. (2011). Thermal and structural study of guava (Psidium guajava L) powders obtained by two dehydration methods. Química Nova, 34(4), 636-640.

Panchev, I. N., Slavov, A., Nikolova, K., \& Kovacheva, D. (2010). On the water-sorption properties of pectin. Food Hydrocolloids, 24(8), 763-769.

Pereira, L. M., Carmello-Guerreiro, S. M., \& Hubinger, M. D. (2009). Microscopic features, mechanical and thermal properties of osmotically dehydrated guavas. LWT - Food Science and Technology, 42(1), 378-384.

Peressini, D., Bravin, B., Lapasin, R., Rizzotti, C., \& Sensidoni, A. (2003). Starchmethylcellulose based edible films: rheological properties of film-forming dispersions. Journal of Food Engineering, 59(1), 25-32.

Piermaria, J. A., de la Canal, M. L., \& Abraham, A. G. (2008). Gelling properties of kefiran, a food-grade polysaccharide obtained from kefir grain. Food Hydrocolloids, 22(8), 1520-1527.

Qiu, N., Tian, Y., Qiao, S., \& Deng, H. (2009). Apple Pectin Behavior Separated by Ultrafiltration. Agricultural Sciences in China, 8(10), 1193-1202.

Re, R., Pellegrini, N., Proteggente, A., Pannala, A., Yang, M., \& Rice-Evans, C. (1999). Antioxidant activity applying an improved ABTS radical cation decolorization assay. Free Radical Biology \& Medicine, 26(9-10), 1231-1237.

Ricardo, D., Andrade, P., Lemus M, R., Carmen, E., \& Perez, C. (2011). Models of sorption isotherms for food: uses and limitations. Vitae, 18(3), 325-334.

Ridley, B. L., O’Neill, M. A., \& Mohnen, D. (2001). Pectins: structure, biosynthesis, and oligogalacturonide-related signaling. Phytochemistry, 57(6), 929-967.

Roos, Y., \& Karel, M. (1990). Differential Scanning Calorimetry Study of Phase Transitions Affecting the Quality of Dehydrated Materials. Biotechnology Progress, 6(2), 159-163.

Saad, A., Touati, B., Draoui, B., Tabti, B., Abdenebi, A., Benaceur, S. (2014). Mathematical Modeling of Moisture Sorption Isotherms and Determination of Isosteric Heats of Sorption of Ziziphus Leaves. Modelling and Simulation in Engineering, Modelling and Simulation in Engineering, 2014, e427842.

Sato, M. D. F., Rigoni, D. C., Canteri, M. H. G., Petkowicz, C. L. de O., Nogueira, A., \& Wosiacki, G. (2011). Chemical and instrumental characterization of pectin from dried pomace of eleven apple cultivars. Acta Scientiarum. Agronomy, 33(3).

Sila, D. n., Van Buggenhout, S., Duvetter, T., Fraeye, I., De Roeck, A., Van Loey, A., \& Hendrickx, M. (2009). Pectins in Processed Fruits and Vegetables: Part II-StructureFunction Relationships. Comprehensive Reviews in Food Science and Food Safety, 8(2), 86104. 
Sousa, A. G., Nielsen, H. L., Armagan, I., Larsen, J., \& Sørensen, S. O. (2015). The impact of rhamnogalacturonan-I side chain monosaccharides on the rheological properties of citrus pectin. Food Hydrocolloids, 47, 130-139.

Takei, T., Sugihara, K., Ijima, H., \& Kawakami, K. (2011). In situ gellable sugar beet pectin via enzyme-catalyzed coupling reaction of feruloyl groups for biomedical applications. Journal of Bioscience and Bioengineering, 112(5), 491-494.

Torres, E., Marín, V., Aburto, J., Beltrán, H. I., Shirai, K., Villanueva, S., \& Sandoval, G. (2012). Enzymatic modification of chitosan with quercetin and its application as antioxidant edible films. Applied Biochemistry and Microbiology, 48(2), 151-158.

Tsami, E., Vagenas, G. k., \& Marinos-Kouris, D. (1992). Moisture sorption isotherms of pectins. Journal of Food Processing and Preservation, 16(3), 151-161.

Urias-Orona, V., Rascón-Chu, A., Lizardi-Mendoza, J., Carvajal-Millán, E., Gardea, A. A., \& Ramírez-Wong, B. (2010). A Novel Pectin Material: Extraction, Characterization and Gelling Properties. International Journal of Molecular Sciences, 11(10), 3686-3695.

Van den Broek, L. A. M., \& Boeriu, C. G. (2013). Enzymatic synthesis of oligo- and polysaccharide fatty acid esters. Carbohydrate Polymers, 93(1), 65-72.

Wallingford, L., \& Labuza, T. P. (1983). Evaluation of the Water Binding Properties of Food Hydrocolloids by Physical/Chemical Methods and in a Low Fat Meat Emulsion. Journal of Food Science, 48(1), 1-5.

Wang, S.-Q., Ravindranath, S., Wang, Y., \& Boukany, P. (2007). New theoretical considerations in polymer rheology: Elastic breakdown of chain entanglement network. The Journal of Chemical Physics, 127(6), 064903.

Wang, X., Chen, Q., \& Lü, X. (2014). Pectin extracted from apple pomace and citrus peel by subcritical water. Food Hydrocolloids, 38, 129-137.

Yuan, M., Galloway, J. A., Hoffman, R. J., \& Bhatt, S. (2011). Influence of molecular weight on rheological, thermal, and mechanical properties of PEEK. Polymer Engineering \& Science, 51(1), 94-102.

Zaidel, D. N. A., Chronakis, I. S., \& Meyer, A. S. (2012). Enzyme catalyzed oxidative gelation of sugar beet pectin: Kinetics and rheology. Food Hydrocolloids, 28(1), 130-140.

Zaidel, D. N. A., \& Meyer, A.-S. (2013). Oxidative enzymatic gelation of sugar beet pectin for emulsion stabilization. Research Journal of Biotechnology, 8(7), 81-86.

Zhang, L., Ye, X., Ding, T., Sun, X., Xu, Y., \& Liu, D. (2013). Ultrasound effects on the degradation kinetics, structure and rheological properties of apple pectin. Ultrasonics Sonochemistry, 20(1), 222-231. 


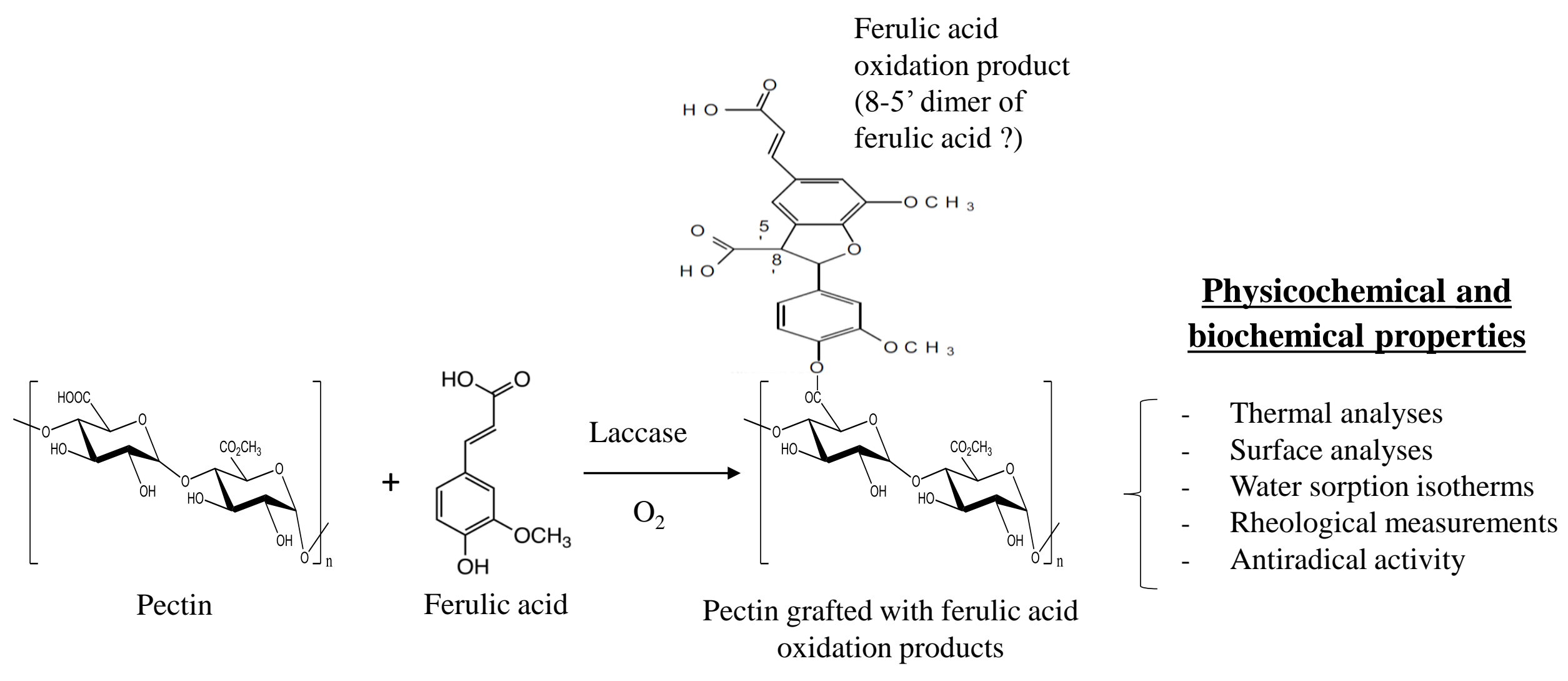




\section{Highlights:}

- The physicochemical properties of pectin grafted with phenols were studied

- The morphological surface and the thermal properties of the pectin were altered

- $\quad$ Pectin grafted with phenols showed a slower gelation rate

- Grafting of phenols enhanced the antioxidant activity of pectin 


\section{Figures Captions}

Figure 1: Scanning Electron Micrograph of native pectin (on the left) and pectin grafted with phenols (on the right)

Figure 2: Sorption isotherm profiles obtained for the native pectin $(\bullet)$ and the pectin grafted with phenols (o), estimated at $25^{\circ} \mathrm{C}$, from 0 to 0.9 of water activity

Figure 3: Variation of the shear viscosity depending on the shear stress for native $(0)$ and modified pectins $(\bullet)\left(1 \% \mathrm{w} / \mathrm{v}\right.$ in water). Viscosities were measured at $25 \pm 1{ }^{\circ} \mathrm{C}$ with coneplate geometry $\left(50 \mathrm{~mm}, 2^{\circ}\right)$, sd. was $\leq 4 \%$

Figure 4: Shear viscosity as a function of the concentration in native and modified pectin. Viscosities were measured at $25 \pm 1{ }^{\circ} \mathrm{C}$ and a fixed rotational shear rate of $2.78 .10^{-4} \mathrm{~s}^{-1}$

Figure 5: Variation of elastic modulus $G^{\prime}\left(\bullet\right.$ and $\circ$ ) (Pa) and viscous modulus $G^{\prime \prime}$ ( $\square$ and $\square$ ) (Pa) with the frequency $(\mathrm{Hz})$ for the native (open symbols) or the modified pectin (filled symbols) at a concentration of $1 \%(\mathrm{w} / \mathrm{v})$

Figure 6: Variation of the storage (G') modulus versus time in a modified pectin solution $(1.25 \%(\mathrm{w} / \mathrm{v})$, in $0.1 \mathrm{~N} \mathrm{NaCl})$, with a volume of calcium corresponding to $\mathrm{R}=(2[\mathrm{Ca} 2+]) /$ $([\mathrm{COO}-])=0.58$ and $\mathrm{pH}$ 6.5. Measurements were performed at $25^{\circ} \mathrm{C}, 1 \mathrm{~Hz}$ and $0.001 \%$ strain

\section{Tables Captions}

Table 1: Temperatures of thermal transitions in native pectin and in pectin grafted with phenolic compounds

Table 2: Capacity of native and modified pectin to scavenge DPPH ${ }^{\bullet}$ and $\mathrm{ABTS}^{\bullet+}$ species, expressed as $\mathrm{EC}_{50}$ values 
Figure 1:
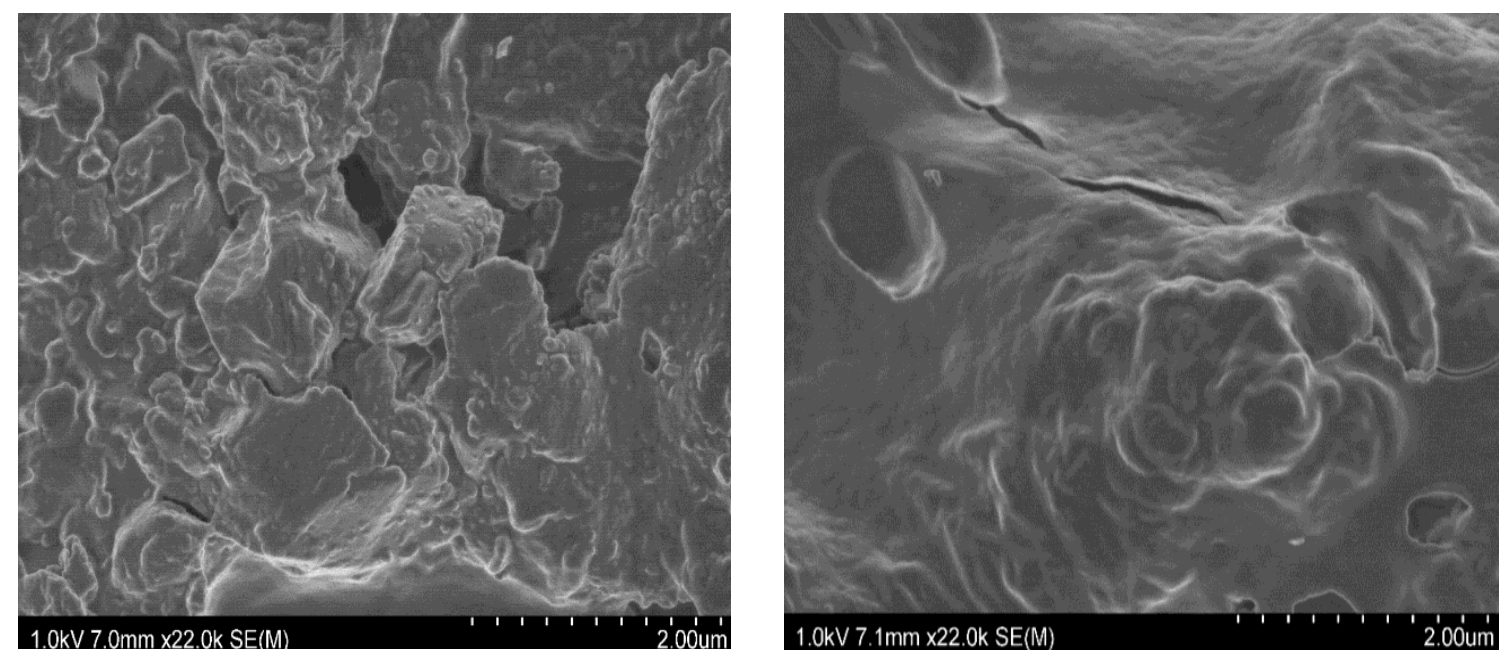

1.0kV7.1mm x22.0k SE(M) 
Figure 2:

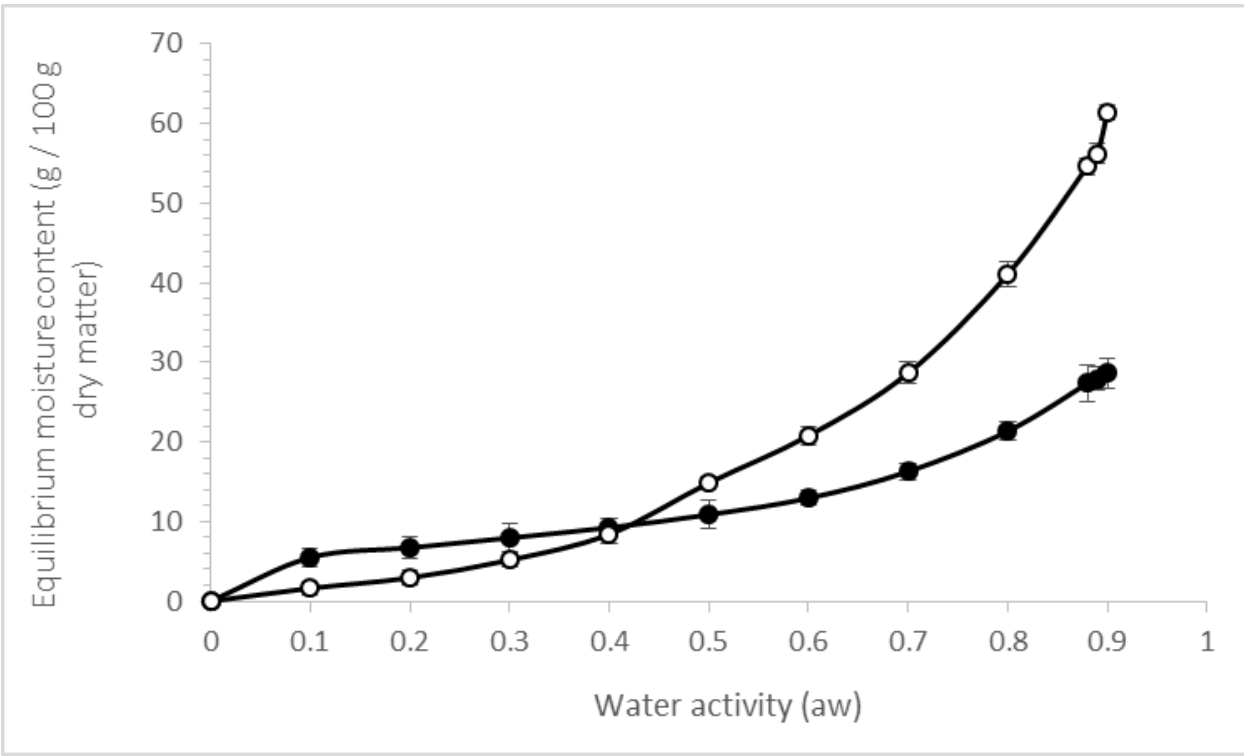


Figure 3:

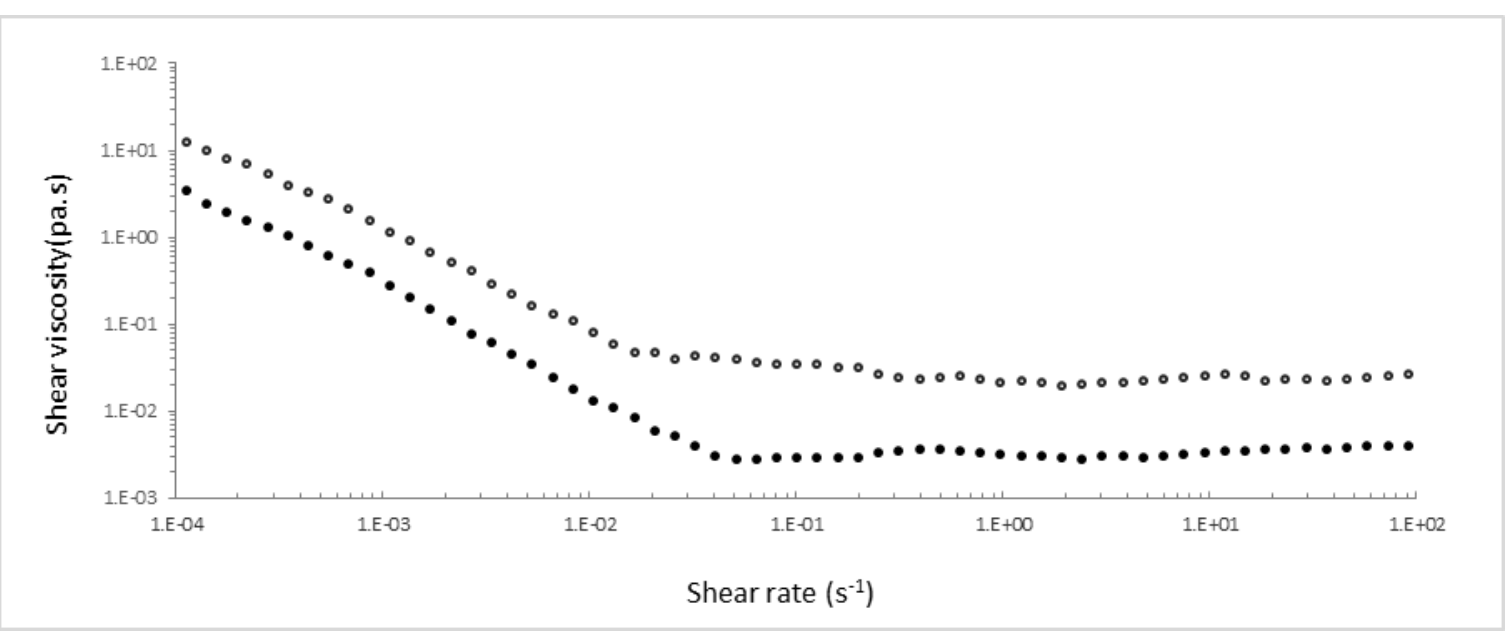


Figure 4:

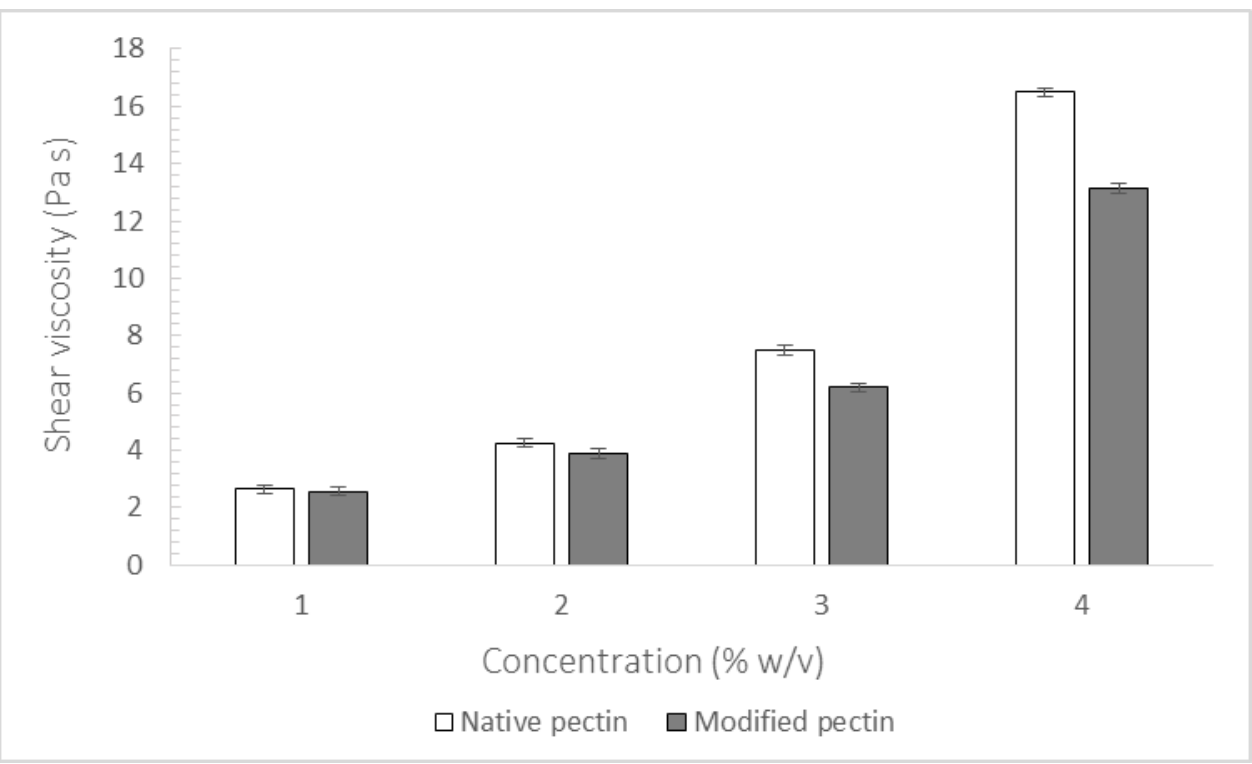


Figure 5:
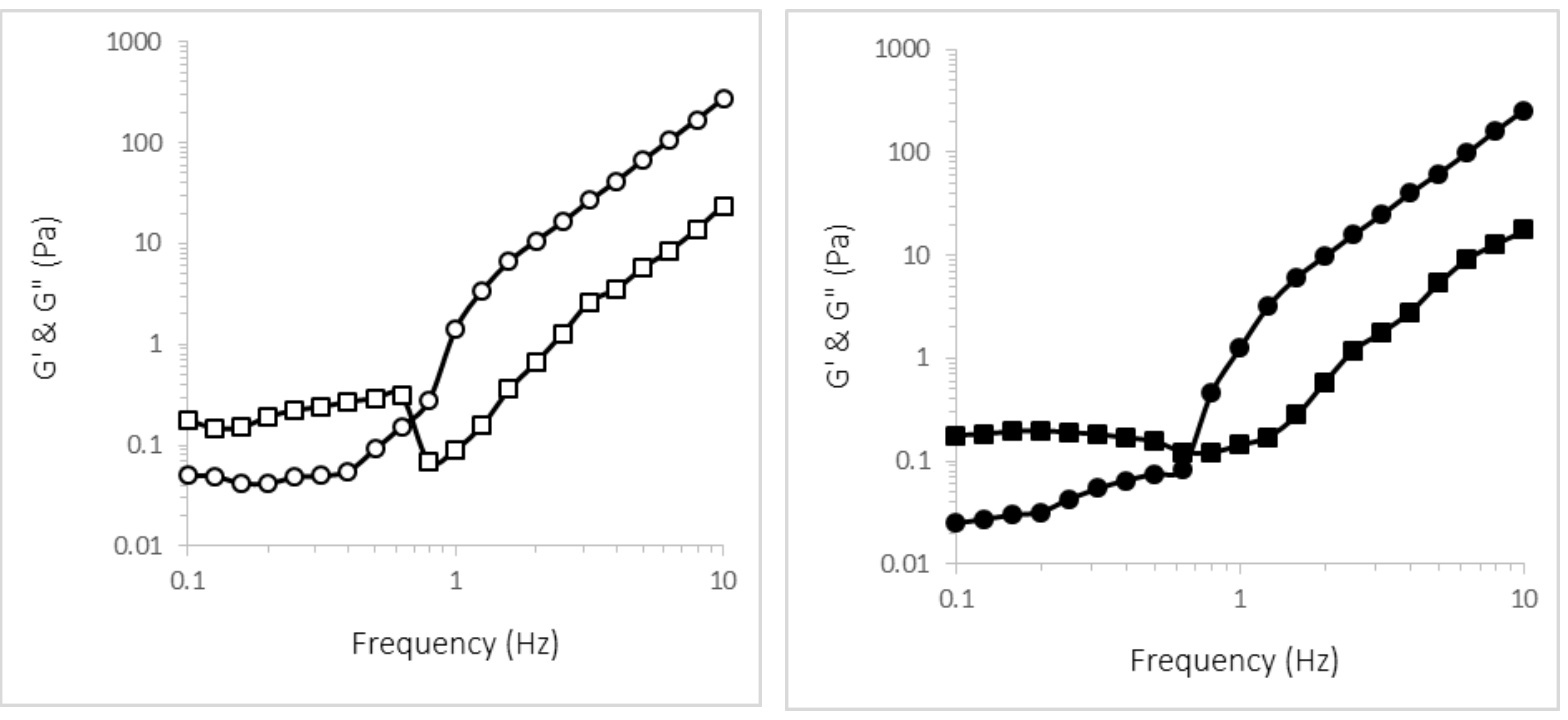
Figure 6:

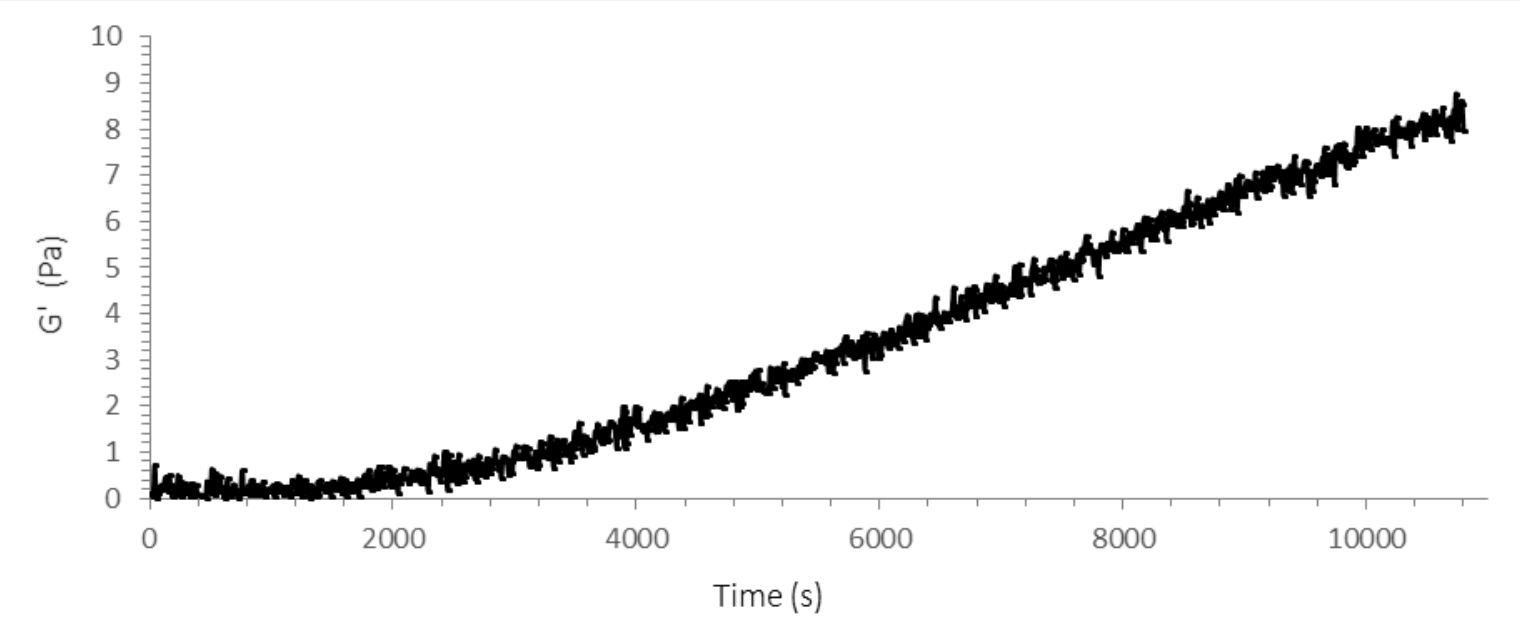


Table 1:

\begin{tabular}{lccc}
\hline DSC analysis & $\mathrm{T}_{\mathrm{g}}\left({ }^{\circ} \mathrm{C}\right)$ & $\mathrm{Tc}\left({ }^{\circ} \mathrm{C}\right)$ & $\mathrm{T}_{\mathrm{m}}\left({ }^{\circ} \mathrm{C}\right)$ \\
\hline Native pectin & $60^{\mathrm{a}}$ & - & $180^{\mathrm{a}}$ \\
Modified pectin & $48^{\mathrm{b}}$ & 130 & $160^{\mathrm{b}}$
\end{tabular}

$\mathrm{T}_{\mathrm{g}}$ : glass transition temperature. $\mathrm{T}_{\mathrm{c}}$ : crystallization temperature. $\mathrm{T}_{\mathrm{m}}$ : melting temperature. Each value is expressed as mean \pm standard deviation $(n=3)$. Values not followed by the same letter in each column are significantly different at the $0.05 \%$ level (Duncan's test). 
Table 2:

\begin{tabular}{lcc}
\hline & $\mathrm{EC}_{50}$ DPPH test $(\mathrm{mg} / \mathrm{mL})$ & $\mathrm{EC}_{50}$ ABTS test $(\mathrm{mg} / \mathrm{mL})$ \\
\hline Native pectin & $29.5 \pm 0.3^{\mathrm{a}}$ & $116.2 \pm 3.9^{\mathrm{a}}$ \\
Modified Pectin & $1.4 \pm 0.2^{\mathrm{b}}$ & $11.2 \pm 0.8^{\mathrm{b}}$ \\
\hline $\begin{array}{l}\text { Each value is expressed as mean } \pm \text { standard deviation }(\mathrm{n}=3) . \\
\text { are significantly different at the } 0.05 \% \text { level (Duncan's test) }\end{array}$
\end{tabular}

